\title{
Study of Power Plant Main Steam Temperature System Based on Smith-LADRC Controller
}

\author{
Jia LUO, Weijian HUANG, Xi ZHANG, Le WU, Kai SU1, a , Yingnan WANG, \\ Siying WANG ${ }^{2, b}$ \\ ${ }^{1}$ Electric Power Research Institute of Guangdong Grid Company, Guangzhou, 510080, China \\ ${ }^{2}$ North China Electric Power University, Beijing, 102206, China \\ aemail: jialuo@126.com, bemail: yingnan120@163.com
}

\begin{abstract}
Keywords: Main steam temperature; Smith ADRC-P cascade control system; robust performance; disturbance rejection
\end{abstract}

\begin{abstract}
Against such characteristics as large delay, nonlinear, time-varying and uncertainty of controlled object, the Smith-LADRC cascade control system is proposed in this paper. The principle of the LADRC is briefly introduced firstly, and then the LADRC-P control system with Smith predictor is designed and the closed loop system is studied in MATLAB simulation. In addition, control effect of the new structure and Smith-P cascade control structure is compared, and the robust performance is analyzed as well. Results show that when using different control strategies for the same load, performance under Smith-LADRC control is better than that under Smith-P control. The new control structure shows excellent control performance, outstanding adaptability and robustness against model uncertainties and external disturbances.
\end{abstract}

\section{Introduction}

In thermal power plant, boiler superheated steam outlet temperature (main steam temperature) is one of the important parameters affecting the security and efficiency of unit [1]. Considering the main steam temperature control system is a typical large inertia, large delay, nonlinear and time-varying system, the system has a complex structure and difficult to control [2]. Therefore it is very important to control the main steam temperature accurately. Many scholars apply various control strategies to main steam temperature control system. Conventional PID cascade control method often fails to obtain satisfactory results. Predicative control strategies, such as Smith method [3], DMC and internal mode control (IMC) are much dependent on precise models of the plants. And many advanced control methods, such as fuzzy control [4], artificial neural network and adaptive control require either information on the system states or an efficient on-line identifier, thus may be difficult to apply in practice. ADRC method was first applied for systems with large time-delay in [5], which proposed a new method for these systems.

Active disturbance rejection control(ADRC) is an object-model independent control method which was first proposed by Prof. Han in 1998 for rejecting disturbance of a nonlinear system [6]. Literature [7] simplified the ADRC design procedure by considering its 'linear' version and then proposed a linear active disturbance rejection control(LADRC). The final tuning parameters for a LADRC are reduced to 3, which greatly simplifies the process of tuning and help develop the LADRC idea and make it an applicable control strategy. By using this method the perfect performance can be obtained for multi-variable control systems with small time-delay, but for main steam temperature control system with large time-delay, the control performance will decline apparently. For the large time-delay plants, Smith Predictor is well used to overcome the effect of large time delay.

Found on the above situation, in this paper a new method for main steam temperature control is presented which combines LADRC-P cascade control with Smith Predictor and the framework of the LADRC-P two-loop cascade control system based on Smith Predictor is also constructed to get better control performance. Finally the effectiveness of the control program is simulated by MATLAB. 


\section{Design and Tuning of LADRC}

The structure of a second-order LADRC is shown in Figure.2.

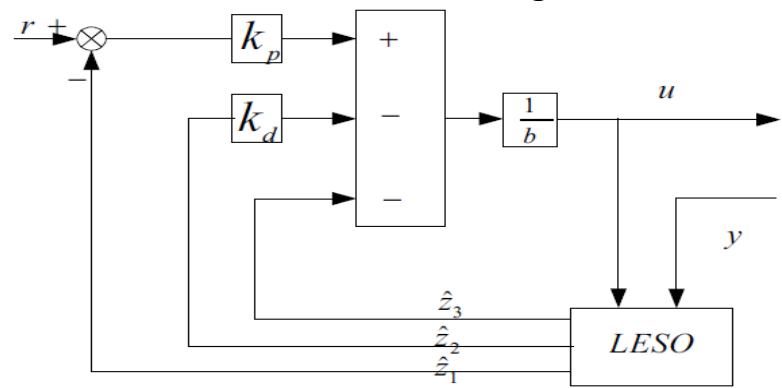

Fig.1. Structure of LADRC

Consider a generalized second-order system given by:

$\ddot{y}=f(\dot{y}, y, \dot{u}, \omega, t)+b u$

where $y$ and $u$ are system output and input respectively, $\omega$ is the external disturbance and $b$ is a constant. The entire $f$ is the uncertainty of the system, which is the combination of the unknown internal dynamics of the system and external disturbance.

And an extended state observer(ESO) is given by:

$z_{1}=y, z_{2}=\dot{y}, z_{3}=f(\dot{y}, y, \dot{u}, \omega, t)$

Assume that $f(\dot{y}, y, \dot{u}, \omega, t)$ is differentiable and let $f(\dot{y}, y, \dot{u}, \omega, t)=h$. The above equation(2) is equivalent to:

$$
\left\{\begin{array}{l}
\dot{z}=A_{0} z+B_{0} u+E_{0} h \\
y=C_{0} z
\end{array}\right.
$$

where

$$
A_{0}=\left[\begin{array}{lll}
0 & 1 & 0 \\
0 & 0 & 1 \\
0 & 0 & 0
\end{array}\right], B_{0}=\left[\begin{array}{l}
0 \\
b \\
0
\end{array}\right], E_{0}=\left[\begin{array}{l}
0 \\
0 \\
1
\end{array}\right], C_{0}=\left[\begin{array}{lll}
1 & 0 & 0
\end{array}\right]
$$

A standard linear observer for (3) can be written as:

$$
\left\{\begin{array}{l}
\dot{\hat{z}}=A_{0} \hat{z}+B_{0} u+L_{0}(y-\hat{y}) \\
\hat{y}=C_{0} \hat{z}
\end{array}\right.
$$

where Lo is the observer gain vector

$$
L_{0}=\left[\begin{array}{lll}
\beta_{1} & \beta_{2} & \beta_{3}
\end{array}\right]^{T}
$$

$\hat{z}_{1}, \hat{z}_{2}, \hat{z}_{3}$ can closely track $y, \dot{y}, f(\dot{y}, y, \dot{u}, \omega, t)$ respectively if the observer gain Lo is chosen properly, thus the generalized disturbance $\mathrm{f}$ is available for control.

The control law is chosen as follow:

$$
u=\frac{-\hat{z}_{3}+u_{0}}{b}
$$

ignoring the observer's estimation error, the plant is reduced to a unit gain double integrator:

$$
\ddot{y}=f(\dot{y}, y, \dot{u}, \omega, t)-\hat{z}_{3}+u_{0} \approx u_{0}
$$

So, the final system can be easily controlled with a traditional PD(Proportional-Derivative) controller:

$$
u_{0}=K_{p}\left(r-\hat{z}_{1}\right)-K_{d} \hat{z}_{2}
$$

where $r$ is the set point, $\mathrm{Kp}$ and $\mathrm{Kd}$ are PD control parameters.

According to parameterization conception in literature [7], for practical reason, the tuning of these two sets of gains are reduced to two tuning parameters: $\omega_{c}$, the controller bandwidth and $\omega_{0}$, the observer bandwidth. For the sake of simplicity and practicality, assume that all observer poles 
are placed at $-\omega_{0}$, so the parameters can be selected with

$\beta_{1}=3 \omega_{0}, \beta_{2}=3 \omega_{0}^{2}, \beta_{3}=\omega_{0}^{3}$

If $\hat{z}_{1}, \hat{z}_{2}$ are accurate, then the final controlled system becomes

$\ddot{y}=u_{0}=K_{p}(r-y)-K_{d} \dot{y}$

The closed-loop transfer function from $r$ to $y$ is:

$G_{c l}=\frac{y(s)}{r(s)}=\frac{K_{p}}{s^{2}+K_{d} s+K_{p}}$

By tuning $\mathrm{Kp}$ and $\mathrm{Kd}$, the closed loop can achieve the desired dynamic performance. Similarly, in order to simplify controller parameters, assume that all two of the controller poles are placed at $-\omega_{c}$, then the tuning of $\mathrm{Kp}$ and $\mathrm{Kd}$ is given by:

$$
K_{d}=2 \omega_{c}, K_{p}=\omega_{c}^{2}
$$

Since the real order of the plant and the gain $b$ are hard to estimate in practice, so sometimes ' $b$ ' can be used as another tuning parameter. So, an LADRC can be tuned with 3 parameters $\omega_{c}$, $\omega_{0}$ and $\mathrm{b}$, thus it is easy to be understood by practical control engineers. In summary, the LADRC has the following state-space form:

$$
\left\{\begin{array}{l}
\dot{\hat{z}}=\left(A_{0}-L_{0} C_{0}\right) \hat{z}+B_{0} u+L_{0} y=\left[\begin{array}{ccc}
-3 \omega_{0} & 1 & 0 \\
-3 \omega_{0}^{2} & 0 & 1 \\
-\omega_{0}^{3} & 0 & 0
\end{array}\right] \hat{z}+\left[\begin{array}{cc}
0 & 3 \omega_{0} \\
b & 3 \omega_{0}^{2} \\
0 & \omega_{0}^{3}
\end{array}\right]\left[\begin{array}{l}
u \\
y
\end{array}\right] \\
u=\frac{K_{p}\left(r-\hat{z}_{1}\right)-K_{d} \hat{z}_{2}-\hat{z}_{3}}{b}=\frac{\omega_{c}^{2}\left(r-\hat{z}_{1}\right)-2 \omega_{c} \hat{z}_{2}-\hat{z}_{3}}{b}
\end{array}\right.
$$

\section{Design of Control Scheme for the Main Steam Temperature System}

Considering the main steam temperature control system is a typical large inertia and large delay system, most power plants use cascade control structure to control the main steam temperature [9]. In this paper, we adopt an improved cascade control system. The secondary loop uses P controller to eliminate bias of the leader region's steam temperature, adjusting the main steam temperature coarsely. The main loop uses LADRC controller, which not only can overcome the external disturbance, such as steam or gas flow, but also has an ability to resist object uncertainty, enhancing the robustness of the control system. Besides, for pure lag and large delay systems, Smith predictor [] has been added in the main loop, which will obviously improve the dynamic performance of the control system. Smith-LADRC main steam temperature cascade control scheme is shown in Figure.2.

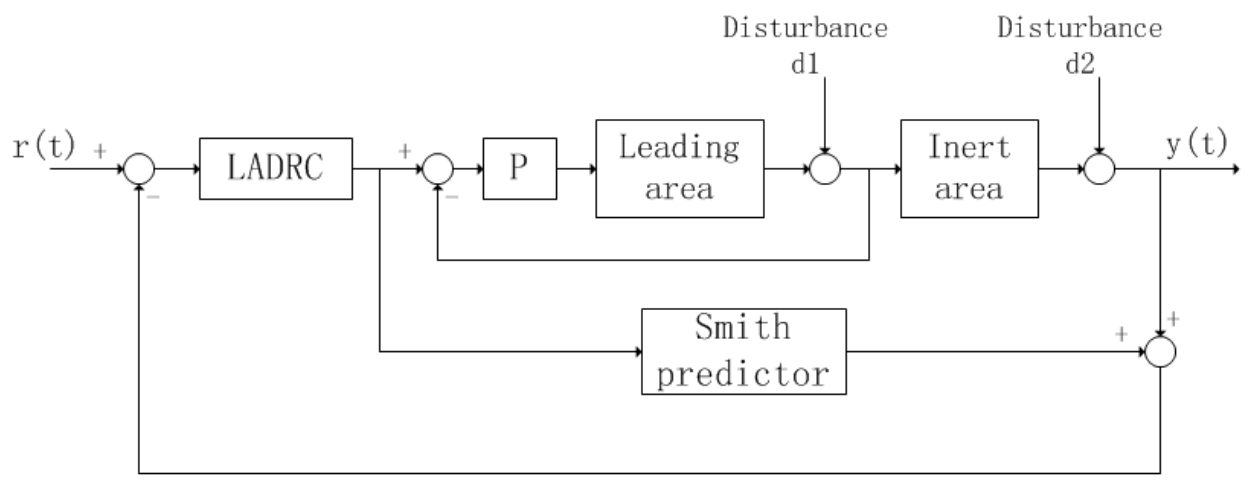

Fig.2. Smith-LADRC main steam temperature cascade control system

The paper adopts four typical loads of a $600 \mathrm{MW}$ supercritical boiler: $37 \%$ load, 50\% load, 75\% load and 100\% load [8]. Table 1 are the dynamic characteristics model of four typical loads when the main steam subjects to spray-water disturbance. Table 2 are the corresponding Smith models of 
controlled object, which consist of a pure time delay and a first-order inertia model. From the Table 1 we can see that when the load changes, there will be an obvious change of the dynamic characteristics of the main steam temperature.

Table 1 Transfer Functions of Four Typical Loads in Main Steam Temperature due to Spray-Water Disturbance

\begin{tabular}{cccc}
\hline \multicolumn{2}{c}{ Load } & Temperature of leading area & Temperature of inert area \\
\hline Load1 & $37 \%$ & $-5.027 /(1+28 s)^{2}$ & $-1.048 /(1+56.6 s)^{8}$ \\
Load2 & $50 \%$ & $-3.067 /(1+25 s)^{2}$ & $-1.119 /(1+42.1 s)^{7}$ \\
Load3 & $75 \%$ & $-1.657 /(1+20 s)^{2}$ & $-1.202 /(1+27.1 s)^{7}$ \\
Load4 & $100 \%$ & $-0.815 /(1+18 s)^{2}$ & $-1.276 /(1+18.4 s)^{6}$ \\
\hline \multicolumn{5}{c}{ Table 2 Smith Models of Controlled Object } \\
\hline \multicolumn{5}{c}{ Load } & First-order inertia model & $G(s)$ & Pure delay $\tau$ \\
\hline Load1 & $37 \%$ & $-1.028 /(1+202 s)$ & 285 \\
Load2 & $50 \%$ & $-1.081 /(1+117 s)$ & 194.5 \\
Load3 & $75 \%$ & $-1.136 /(1+90 s)$ & 85.5 \\
Load4 & $100 \%$ & $-1.135 /(1+36 s)$ & 117 \\
\hline
\end{tabular}

\section{Test results}

In LADRC-Smith cascade control system, LADRC parameters are tuned for the plant at $75 \%$ load, since the plant dynamics at $75 \%$ load are the most typical ones. According to the tuning method mentioned above, the parameters of the 2nd-order LADRC are given by:

$$
b=0.001, \omega_{0}=0.05, K_{p}=0.0005, K_{d}=0.008
$$

Meanwhile, PID-Smith cascade control for main steam temperature system is also simulated in this paper as comparison. PID parameters are tuned at same load, which are chosen as:

$$
k_{p}=-0.3148, k_{i}=-0.00717, k_{d}=30.935
$$

Parameter Kp in secondary loop remains the same in two control schemes which is chosen as: $K_{p}=-10$.

The models built by SIMULINK are shown as Fig.3 and Fig.4. Fig.3 is internal structure of LADRC and Fig. 4 is 75\% load under Smith LADRC-P cascade control system. Similarly, we can build the models of other loads.

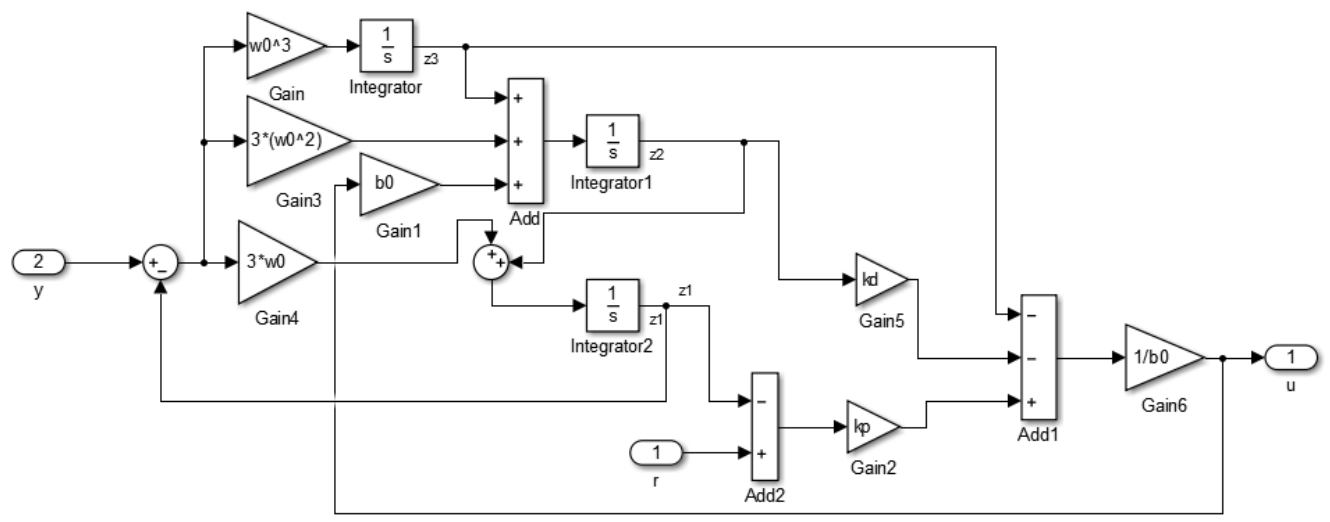

Fig.3. Internal structure of LADRC 


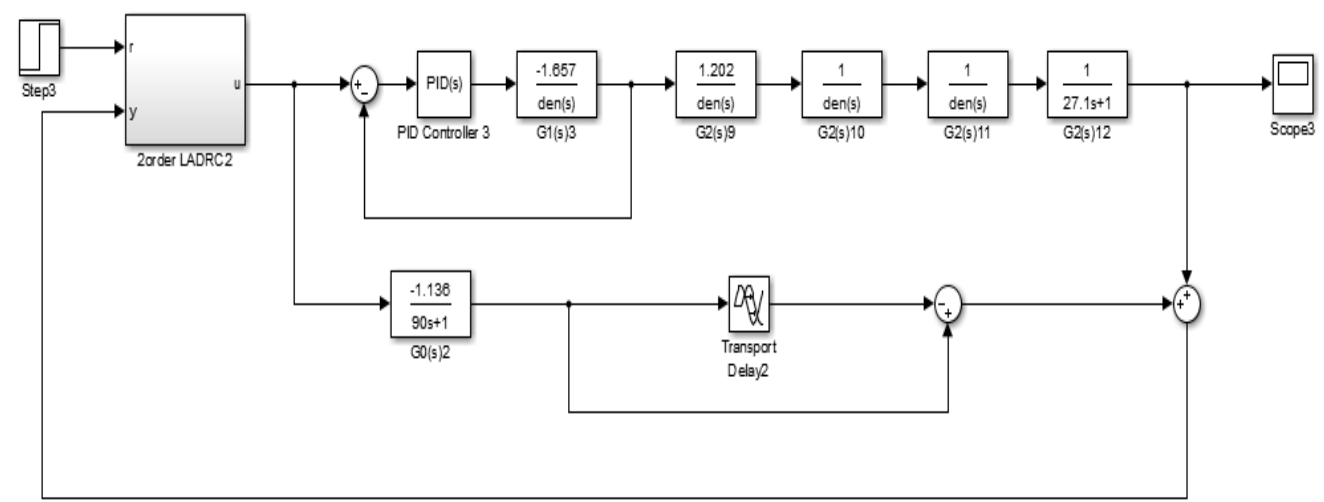

Fig. 4. 75\% Load under Smith LADRC-P cascade control system

In this paper, LADRC-Smith cascade control is compared with PID-Smith cascade control at four typical rated loads by simulation approach. Remain controller parameters unchanged, the step responses for the closed-loop system are shown in Figure.5.

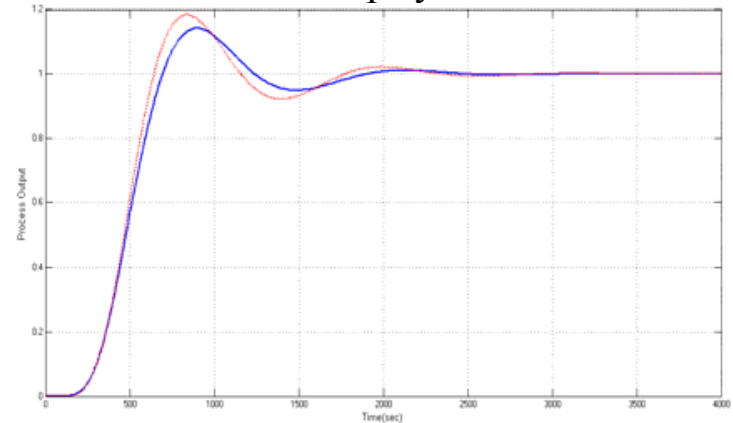

(a) Responses for $37 \%$ load

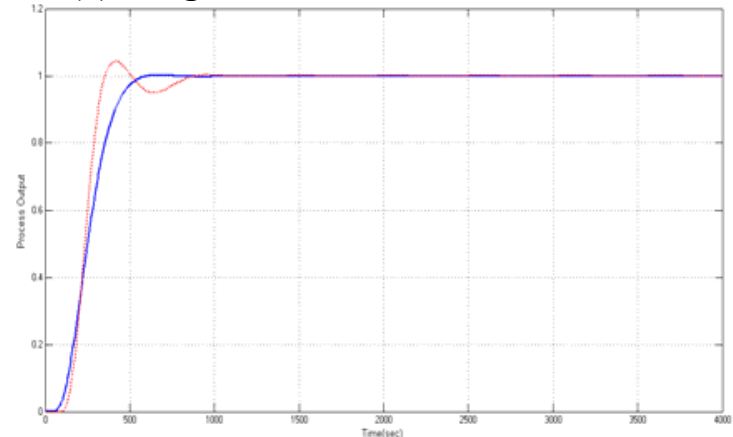

(c) Responses for $75 \%$ load

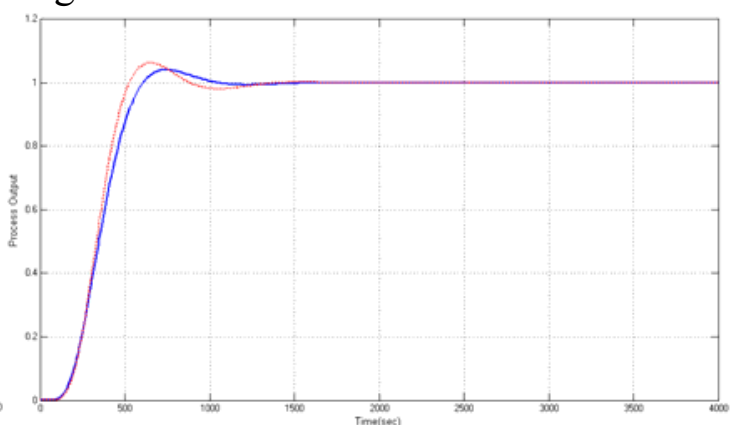

(b) Responses for $50 \%$ load

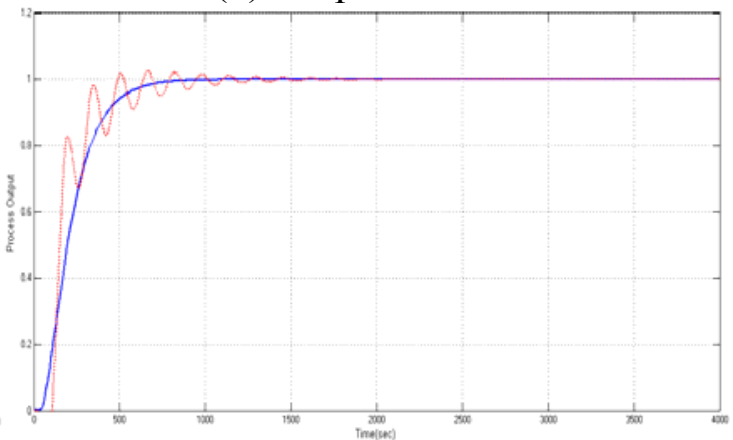

(d) Responses for $100 \%$ load

Fig.5. Step responses for four typical rated loads (blue: LADRC-Smith, red: PID-Smith)

LADRC is used to improve disturbance rejection performance instead of tracking. Taking the plant model at $75 \%$ load for example, a step disturbance occurs in the input d1(internal disturbance) and $\mathrm{d} 2$ (external disturbance)at $\mathrm{t}=1000$ respectively, which represents uncertainties or disturbances in leading area and inert area. Disturbance rejection performance of two control strategies are shown in Figure.6.

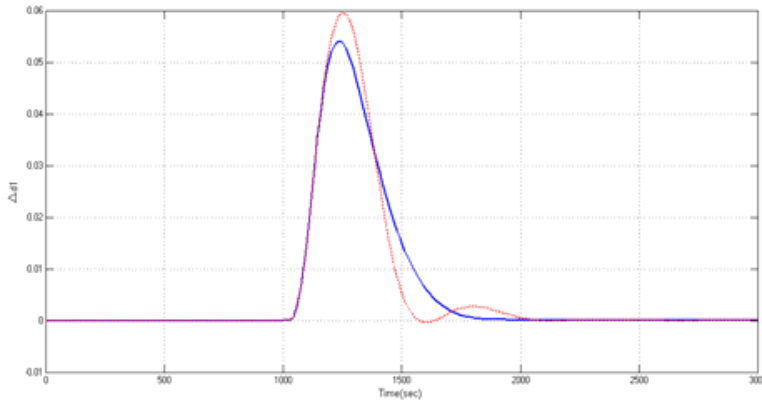

(a) Internal disturbance (d1) responses

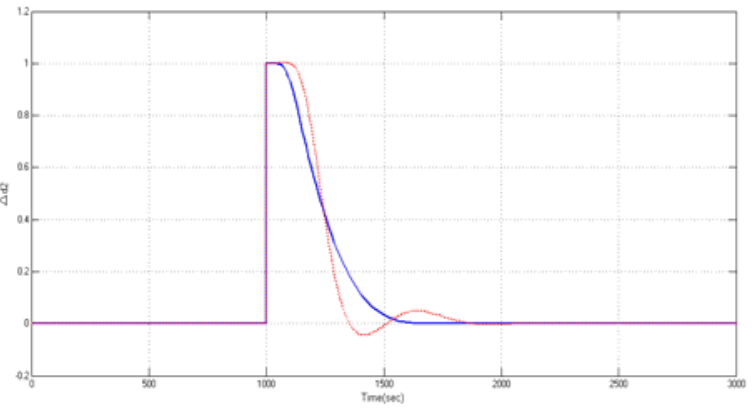

(b) External disturbance $(\mathrm{d} 2)$ responses

Fig.6. Disturbance responses for 75\% load (blue: LADRC-Smith, red: PID-Smith)

From the above figures, simulation results show that LADRC rejects the disturbances more 
quickly and disturbance responses of LADRC have smaller fluctuation compared with the PID controller. So the proposed method can achieve better control performance and robustness than the PID-Smith controller and is of value for engineering application in main steam temperature system.

\section{Conclusion}

A Smith-LADRC cascade control scheme was proposed for main steam temperature of a $600 \mathrm{MW}$ supercritical boiler was studied. It compromises a Smith predictor and LADRC-P controllers. The Smith predictor is used to overcome the effect of large time delay in thermal power plant and LADRC-P controllers are used to further reduce the disturbances and model uncertainties. This paper LADRC-Smith control performance is compared with Smith-PID control performance at four typical rated loads by simulation approach. Comparison results show that with the same load, systems under Smith-LADRC control have the better performance than that under Smith-PID control. In conclusion the Smith-LADRC cascade control structure can achieve better disturbance rejection performance and robustness and is worth to implement in practice.

\section{References}

[1] Y. Z. Yu, Z. B. Zhang, H. C. Xu, D. G. Chen, G. J. Dong, B. Shen, S. Liu. "Investigation for 600 MW Supercritical Boiler's Main Steam Temperature Control," Proceedings of the 2010 International Conference on Electrical and Control Engineering (ICECE 2010), p 3848-51, 2010

[2] J. T. Zhang, W. Wang, F. Cao. "Application of an intelligent control method in 300MW unit main steam temperature control system," Chinese Society for Electrical Engineering, vol. 19, no. 3, (1999), pp. 6-10.

[3] S. Lee, Y. Shin, E. Jang, Hwi-Beom, Shin. "New Smith Predictor Control Using Disturbance Observer for Steam Superheater and Steam Pressure of the Boiler," Hanoi: Control, Automation, Robotics and Vision, 2008. ICARCV 2008. 10th International Conference on, 2008. 979-981.

[4] J. Zeng, Y. Xie, L. Chen. "Design of Main Steam Temperature Cascade Control System Based on Fuzzy Self-tuning PID Controller," Hunan: Intelligent Computation Technology and Automation (ICICTA), 2008 International Conference on, 2008. 878-881.

[5] J. Han, W. Zhang. "Active Disturbance Rejection Control for systems with large time delay(in Chinese)" Control and Decision, 1999, 14(4): 354-358.

[6] J. Han. "Active disturbance rejection controller and its applications (in Chinese)," Control and Decision, 1998,13(1):19-23.

[7] J. Gao. "Active disturbance rejection control: A paradigm shift in feedback control system design," American Control Conference, 2006. IEEE, 2006: 7 pp.2399-2405.

[8] Y. S. Fan, Z. G. Xu. "Adaptive fuzzy control of superheated steam temperature control based on dynamic analysis," Proceeding of the CSEE, 1997, 17(1) : 23-28.

[9] Q. Z. Li, Y. G. Niu, B. L. Lu and Z. C. Lan, "Performance evaluation of thermal power plant superheated steam temperature control system," Electric Power Science and Engineering, vol. 27, no. 7, (2011), pp. 45-49.

[10]L. X. Zhang, A. Q. Jiang, Dongchen Han. "The big capacity boiler superheated steam temperature fuzzy-smith control system," Intelligent Control and Automation, 2002. Proceedings of the 4th World Congress on, 2002. 1872-1876. 